\title{
Superiority of moderate control of hyperglycemia to tight control in patients undergoing coronary artery bypass grafting
}

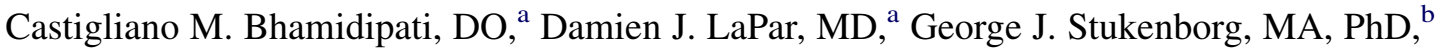 \\ Christine C. Morrison, MSN, ${ }^{\mathrm{a}}$ John A. Kern, MD, ${ }^{\mathrm{a}}$ Irving L. Kron, MD, ${ }^{\mathrm{a}}$ and Gorav Ailawadi, MD ${ }^{\mathrm{a}}$
}

Objective: Although consensus in cardiac surgery supports tight control of perioperative hyperglycemia (glucose $<120 \mathrm{mg} / \mathrm{dL}$ ), recent studies in critical care suggest moderate glycemic control may be superior. We sought to determine whether tight control or moderate glycemic control is optimal after coronary artery bypass grafting.

\begin{abstract}
Methods: From 1995 to 2008, a total of 4658 patients with known diabetes or perioperative hyperglycemia (preoperative glycosylated hemoglobin $\geq 8$ or postoperative serum glucose $>126 \mathrm{mg} / \mathrm{dL}$ ) underwent isolated coronary artery bypass grafting at our institution. Patients were stratified into 3 postoperative glycemic groups: tight ( $\leq 126 \mathrm{mg} / \mathrm{dL})$, moderate $(127-179 \mathrm{mg} / \mathrm{dL})$, and liberal ( $\geq 180 \mathrm{mg} / \mathrm{dL})$. Preoperative risk factors, glycemic management, and postoperative outcomes were analyzed.
\end{abstract}

Results: Operative mortality was 2.5\% (119/4658); major complication rate was 12.5\% (581/4658). Relative to moderate group, more patients in tight group had preoperative renal failure (tight 16.4\%, 22/134, moderate $8.3 \%, 232 / 2785, P=.001$ ) and underwent emergent operations (tight $5.2 \%, 7 / 134$, moderate 1.9\%, 52/ $2785, P=.007)$; however, Society of Thoracic Surgeons predicted mortality risk was lower in tight group $(P<.001)$. Moderate group had lowest mortality (tight 2.9\%, 4/134, moderate 2.0\%, 56/2785, liberal 3.4\%, $59 / 1739, P=.02)$ and incidence of major complications (tight 19.4\%, 26/134, moderate 11.1\%, 308/2785, liberate $14.2 \%, 247 / 1739, P<.001$ ). Risk-adjusted major complication incidence (adjusted odds ratio $0.7,95 \%$ confidence interval $0.58-0.87$ ) and mortality (adjusted odds ratio 0.6 , 95\% confidence interval $0.37-0.83$ ) were lower with moderate glucose control than with tight or liberal management.

Conclusions: Moderate glycemic control was superior to tight glycemic control, with decreased mortality and major complications, and may be ideal for patients undergoing isolated coronary artery bypass grafting. (J Thorac Cardiovasc Surg 2011;141:543-51)

Diabetes mellitus is a well-documented risk factor for coronary artery disease and is common among patients who undergo coronary revascularization. In addition to patients with known diabetes, many patients acquire perioperative insulin resistance and stress-induced hyperglycemia after coronary artery bypass grafting (CABG) procedures. ${ }^{1}$ Postoperative glycemic control in critically ill patients after general and cardiovascular surgical procedures has become a debated issue among trained intensivists. ${ }^{2-4}$ Data in the

\footnotetext{
From the Division of Thoracic and Cardiovascular Surgery, ${ }^{\mathrm{a}}$ Department of Surgery, and the Division of Biostatistics and Epidemiology, ${ }^{\mathrm{b}}$ Department of Public Health Sciences, University of Virginia School of Medicine, Charlottesville, Va.

Supported by T32/HL007849 (to C.M.B., D.J.L.) from the National Heart, Lung, and Blood Institute. The content is solely the responsibility of the authors and does not necessarily represent the official views of the National Heart, Lung, and Blood Institute or the National Institutes of Health. Also supported by Thoracic Surgery Foundation for Research and Education Research Grant (to G.A.).

Disclosures: Authors have nothing to disclose with regard to commercial support.

Read at the 90th Annual Meeting of The American Association for Thoracic Surgery, Toronto, Ontario, Canada, May 1-5, 2010.

Received for publication April 29, 2010; revisions received Aug 7, 2010; accepted for publication Oct 1, 2010; available ahead of print Dec 16, 2010

Address for reprints: Gorav Ailawadi, MD, University of Virginia Health System, PO Box 800679, Charlottesville, VA 22908 (E-mail: gorav@ virginia.edu). $0022-5223 / \$ 36.00$

Copyright (C) 2011 by The American Association for Thoracic Surgery doi:10.1016/j.jtcvs.2010.10.005
}

past have suggested that tight control of postoperative serum glucose after cardiac surgery is the optimal approach, and tight control has therefore become the classically accepted treatment paradigm. ${ }^{5,6}$

Several previous studies have evaluated hyperglycemia in critically ill patients, including those undergoing cardiac surgery. In a landmark randomized trial, Van den Berghe and colleagues ${ }^{7}$ reported a $3 \%$ mortality benefit with intensive insulin therapy (target serum glucose, $80-110 \mathrm{mg} / \mathrm{dL}$ ) relative to conventional treatment (target serum glucose, 180-200 mg/dL). ${ }^{7}$ Similarly, the Portland Diabetic Project, a nonrandomized, prospective protocol, has demonstrated that tight perioperative glycemic control with continuous insulin infusion, relative to sliding-scale intermittent subcutaneous insulin, is safe in reducing serum glucose to nearly euglycemic levels, with decreased mortality, lessened infection, and shorter stay after open cardiac procedures. ${ }^{8-10}$ Collectively, these studies have led to the accepted tight control strategy for postoperative glucose management after cardiac surgery.

In contrast, recent reports in critical care that included cardiac surgical patients have suggested that tight glucose control $(80-110 \mathrm{mg} / \mathrm{dL})$ in the intensive care unit (ICU) results in worse mortality than standard control $(\leq 180$ $\mathrm{mg} / \mathrm{dL})^{2,11,12}$ Although The Society of Critical Care of 


\section{Abbreviations and Acronyms

$\begin{array}{ll}\text { CABG } & \text { coronary artery bypass grafting } \\ \text { CDR } & =\text { Clinical Data Repository } \\ \text { ICU } & =\text { intensive care unit } \\ \text { NICE- } & =\text { Normoglycemia in Intensive Care } \\ \text { SUGAR } & \text { Evaluation-Survival Using Glucose } \\ & \text { Algorithm Regulation [trial] } \\ \text { STS } & \text { Society of Thoracic Surgeons }\end{array}$

Medicine supports close glucose monitoring in the intensive setting, specific definitions for the ideal strategy have not been clarified as of the most recent consensus statement (June 2009). ${ }^{13}$ A recent meta-analysis of 29 randomized trials reported no significant difference in mortality when stratified by glucose goal (very tight $\leq 110 \mathrm{mg} / \mathrm{dL}$ vs moderately tight $<150 \mathrm{mg} / \mathrm{dL}$ ) or intensive care setting in surgical, medical, and mixed medical and surgical patients. ${ }^{14}$ These authors concluded that tight glucose control was associated with decreased septicemia but significantly increased risk of hypoglycemia. ${ }^{14}$

To further support these new findings, the NICE-SUGAR (Normoglycemia in Intensive Care Evaluation-Survival Using Glucose Algorithm Regulation) trial demonstrated a $2.8 \%$ mortality benefit with standard control relative to tight control in medical and surgical patients, including those in cardiovascular ICUs. ${ }^{15}$ Importantly, 3 contemporary prospective trials ${ }^{2,16,17}$ in medical and combined medical-surgical intensive care patients were unable to replicate the initial report by Van den Berghe.

Taken together, these conflicting results suggest that the optimal management of postoperative serum glucose levels in patients after cardiac surgery remains debatable. In light of recent findings advocating moderate glucose control in critically ill patients, ${ }^{15,18}$ we performed a retrospective review at our institution to delineate more clearly an ideal strategy for postoperative glucose management after isolated coronary revascularization.

\section{MATERIALS AND METHODS \\ Data Source}

Institutional data stripped of patient identifiers from 1995 through 2008 were obtained from the University of Virginia Health System Clinical Data Repository (CDR). The CDR is maintained by the Division of Clinical Informatics, Department of Public Health Sciences, and contains patient information managed through the University of Virginia Health System. The CDR collects data and links the cardiac surgical-related information at our institution on the basis of variables defined by the Society of Thoracic Surgeons (STS) national database. ${ }^{19}$ All variables analyzed represent STS definitions. Cases with data missing completely at random were not excluded from analysis; however, variables with large missing data underwent casewise deletion. Approval for this investigation, including patient consent waiver, was obtained by the human investigation committee at the University of Virginia (HSR 14832).

\section{Patient Selection}

We identified 8662 patients who underwent isolated CABG during this study period at our institution. Patients were selected if they had known diabetes mellitus or preoperative glycosylated hemoglobin of at least 8 , or if they had evidence of perioperative hyperglycemia, either (1) immediate postoperative serum glucose level greater than $126 \mathrm{mg} / \mathrm{dL}$ or (2) 3-day postoperative average serum glucose level greater than $126 \mathrm{mg} / \mathrm{dL}$. Patient selection criteria were developed to capture patients with diabetes, poorly controlled or undiagnosed diabetes mellitus, and stress-induced insulin resistance. The perioperative period was defined from the day of surgery through 3 days after the procedure, because as this period has been shown to be critical for glycemic control after cardiac surgery. ${ }^{20,21}$

\section{Glycemic Control Groups}

Patients were stratified into 3 arbitrary postoperative glycemic groups, which were adapted from the World Health Organization guidelines ${ }^{22}$ and based on 3-day average postoperative serum glucose levels. The tight group was composed of those patients with average serum glucose not more than $126 \mathrm{mg} / \mathrm{dL}$, the moderate group was composed of patients with average serum glucose levels of 126.1 to $179.9 \mathrm{mg} / \mathrm{dL}$, and the liberal group was composed of patients with average serum glucose of at least $180 \mathrm{mg} / \mathrm{dL}$.

Serum glucose levels reported through the CDR reflected point-of-care testing. Glucose levels for each postoperative day were not tabulated, and as such the average glucose level reported reflects the cumulative aggregate of all available reported serum glucose measurements of patients receiving insulin therapy, irrespective of location in the hospital. Glucose measurements were performed at least every 2 hours by protocol. The postoperative average data reflect all measurements collected after the patient's arrival in the thoracic and cardiovascular ICU through 72 hours after ICU admission.

Hypoglycemia was defined as any reported serum glucose level of 60 $\mathrm{mg} / \mathrm{dL}$ or less. Symptoms (tachycardia, diaphoresis, anxiety, and so on) were not included to identify hypoglycemic events, because patients in this study were frequently receiving $\beta$-blockade, intravenous inotropic support, or sedation, and also could be mechanically ventilated. Thus the intrinsic catecholamine-mediated physiologic response to hypoglycemia is potentially masked in the ICU setting.

\section{Statistical Analysis}

Primary outcomes of interest were mortality and major complication rate. A major complication was defined to include permanent stroke, renal failure as defined by the STS, prolonged ventilation ( $>24$ hours), deep sternal wound infection, or reoperation for any reason.

The strength of association for each variable was measured with appropriate statistical hypothesis testing. The statistical significance of differences in proportions for categoric variables was evaluated by the Pearson $\chi^{2}$ or Fisher's Exact test where appropriate. The statistical significance of differences in mean values for continuous variables was assessed with single-factor analysis of variance models. Results for the total series of hypothesis tests conducted in the study population were corrected for multiple comparison bias by adjusting each probability by the false discovery rate. Data are shown as numbers and percentages by group or as mean $\pm \mathrm{SD}$, except where indicated otherwise.

Separate multivariable logistic regression models were developed to calculate the adjusted odds of mortality and major complication rate. Variables for the models were selected a priori on the basis of the established literature to control for differences in patient demographic characteristics, risk factors, operative features, and type of postoperative glucose management strategy. The liberal group was used for comparative reference, because a glucose level greater than $180 \mathrm{mg} / \mathrm{dL}$ has been well documented to be detrimental and the tight control group was not an appropriate reference because of its small size. The $95 \%$ confidence intervals for all covariates in the models were calculated. The models' predictive capacity to 
discriminate was measured with the area under the receiver-operator characteristic curve. The Hosmer-Lemeshow $\chi^{2}$ test for goodness-of-fit was performed to assess differences in model calibration for deciles of model probabilities. Relative magnitude of the calculated Wald statistic was used to determine the contribution of each covariate to the regression model. Adjusted odds ratios are presented for each covariate, along with their $95 \%$ confidence intervals. All data were analyzed with the Statistical Package for the Social Sciences 17 software (SPSS Inc, an IBM Company, Chicago, Ill).

\section{RESULTS}

\section{Perioperative Glucose Management}

A total of 4658 patients were identified, including 4433 $(95.2 \%)$ who underwent primary CABG and $225(4.8 \%)$ who underwent reoperative CABG. Average perioperative glucose level was stratified according to postoperative glucose group (Figure 1). Serum glucose averages ranged between $118.9 \mathrm{mg} / \mathrm{dL}$ and $214.6 \mathrm{mg} / \mathrm{dL}$. Despite 25 patients $(0.5 \%)$ with preoperative (day of surgery) serum glucose measurements of $60 \mathrm{mg} / \mathrm{dL}$ or less, there were only 16 patients $(0.3 \%)$ whose first postoperative serum glucose level was in the hypoglycemic range. There were 2 patients in the tight group $(1.5 \%)$ who had preoperative serum glucose levels of $60 \mathrm{mg} / \mathrm{dL}$ or less on the day of surgery. Interestingly, mean initial preoperative glucose level was incrementally higher in the tight control group $(133.7 \mathrm{mg} / \mathrm{dL})$ than in the moderate control group (124.5 mg/dL). Postoperatively, a hypoglycemic reading on the first serum glucose level was proportionally most common in the tight control group (tight $1.5 \%, 2 / 132$, moderate $0.4 \%, 12 / 2773$, and liberal $0.1 \%, 2 / 1737, P=.02)$.

\section{Risk Factors and Operative Features of Patients Undergoing Isolated CABG}

Preoperative risk factors and operative features of patients were analyzed by postoperative serum glucose level (tight, moderate, or liberal). There were notable differences between glucose groups (Table 1). The tight group (3-day postoperative serum glucose average, $\leq 126 \mathrm{mg} / \mathrm{dL}$ ) had the greatest proportion of patients with known diabetes,

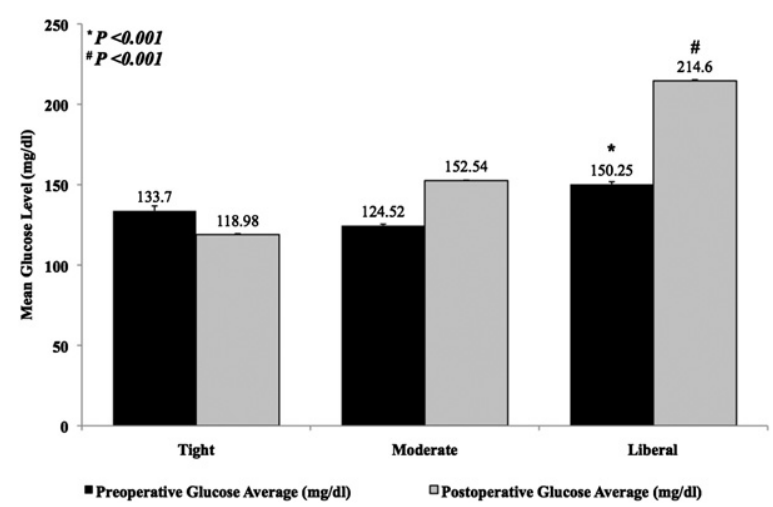

FIGURE 1. Perioperative glucose management by group. Data shown reflect mean $\pm \mathrm{SEM}$ of serum glucose levels. whereas the moderate group (3-day postoperative serum glucose average, $126.1-179.9 \mathrm{mg} / \mathrm{dL}$ ) had the fewest. Preoperative renal failure was lowest in the liberal control group and highest in the tight control group $(P=.001)$. Steroid use was most common in the tight control group $(P<.001)$. The tight group also had the greatest proportion of patients in New York Heart Association functional class IV congestive heart failure relative to the other groups $(P<.001)$. Liberal group patients were more likely to have undergone an elective operation $(P<.001)$, whereas those in the tight group were more likely to have undergone an urgent operation $(P<.001)$ or an emergent operation $(P=.003)$. The moderate group had minimally different yet statistically shorter crossclamp time $(P=.05)$ and perfusion time $(P<.001)$ than did the other groups. Despite these clinical differences, the STS predicted mortality risk for the tight group was lower than that for the moderate group (tight $0.2 \% \pm 1.1 \%$, moderate $0.9 \% \pm 1.9 \%$, $P<.001)$.

\section{Outcomes After Isolated CABG Stratified by Postoperative Glucose Level}

In contrast to their preoperative glucose level on the day of surgery, the first postoperative glucose level was lowest in the tight control group (tight $115.2 \pm 29.3 \mathrm{mg} / \mathrm{dL}$, moderate $126.2 \pm 41.5 \mathrm{mg} / \mathrm{dL}$, and liberal group $178.3 \pm 65.6$ $\mathrm{mg} / \mathrm{dL}, P<.001)$. The incidences of postoperative stroke and deep sternal wound infection were similar across groups (Table 2). Sepsis, prolonged ventilation, postoperative renal failure, and the need for new dialysis were highest in the tight glucose group. Relative to patients in the tight control group, those in the moderate control group on average had a 2-day shorter postoperative stay $(P=.001)$. Importantly, major complication rate and mortality were lowest in the moderate glucose group (Figure 2).

\section{Independent Predictors of Mortality}

Multivariable regression identified age, female sex, preoperative renal failure, left ventricular ejection fraction, and previous coronary revascularization as highly predictive of mortality (area under the curve, 0.84). Importantly, even when controlling for the significant differences between groups, the risk-adjusted odds of mortality were reduced by $40 \%$ with moderate control relative to liberal management (Table 3). Tight glucose control did not independently influence mortality.

\section{Independent Predictors of Major Complication Rate}

Similar to mortality, multivariable regression identified age, female sex, preoperative renal failure, left ventricular ejection fraction, and previous coronary revascularization as predictors of major complications (area under the curve, 0.76). In addition, nonelective surgery was also highly predictive of major complications. Importantly, although tight 
TABLE 1. Risk factors and operative features by glucose management group

\begin{tabular}{|c|c|c|c|c|}
\hline Variables & Tight $(n=134)$ & Moderate $(\mathbf{n}=\mathbf{2 7 8 5})$ & Liberal $(n=1739)$ & $P$ value \\
\hline \multicolumn{5}{|l|}{ Preoperative } \\
\hline Patient age (y, mean \pm SD) & $64.4 \pm 11.4$ & $64.2 \pm 10.6$ & $63.7 \pm 9.9$ & .19 \\
\hline \multicolumn{5}{|l|}{ Sex (no.) } \\
\hline Female & $44(32.8 \%)$ & $661(23.7 \%)$ & $488(28.1 \%)$ & .001 \\
\hline Male & $90(67.2 \%)$ & $2124(76.3 \%)$ & $1251(71.9 \%)$ & .001 \\
\hline \multicolumn{5}{|l|}{ Risk factor (no.) } \\
\hline Stroke & $6(4.5 \%)$ & $419(15.0 \%)$ & $266(15.3 \%)$ & .93 \\
\hline Peripheral arterial disease & $31(23.1 \%)$ & $462(16.6 \%)$ & $322(18.5 \%)$ & .06 \\
\hline Diabetes* & $71(52.9 \%)$ & $929(33.4 \%)$ & $848(48.7 \%)$ & \\
\hline Hypertension & $110(82.1 \%)$ & $2038(73.2 \%)$ & $1231(70.8 \%)$ & .009 \\
\hline Dialysis* & $12(8.9 \%)$ & $48(1.7 \%)$ & $19(1.1 \%)$ & \\
\hline Renal failure & $22(16.4 \%)$ & $232(8.3 \%)$ & $127(7.3 \%)$ & .001 \\
\hline Atrial tachycardia or fibrillation & $9(6.7 \%)$ & $193(6.9 \%)$ & $123(7.1 \%)$ & .98 \\
\hline Ventricular tachycardia or fibrillation & $3(2.2 \%)$ & $68(2.4 \%)$ & $72(4.1 \%)$ & .005 \\
\hline Steroids* & $8(5.9 \%)$ & $68(2.4 \%)$ & $45(2.6 \%)$ & \\
\hline \multicolumn{5}{|l|}{ New York Heart Association functional class (no.) } \\
\hline$I^{*}$ & $6(4.5 \%)$ & $312(11.2 \%)$ & $409(23.5 \%)$ & \\
\hline $\mathrm{II}^{*}$ & $26(19.4 \%)$ & $550(19.8 \%)$ & $696(40.0 \%)$ & \\
\hline III* & $46(34.3 \%)$ & $961(34.5 \%)$ & $384(22.1 \%)$ & \\
\hline $\mathrm{IV}^{*}$ & $56(41.8 \%)$ & $962(34.5 \%)$ & $250(14.4 \%)$ & \\
\hline $\begin{array}{l}\text { Day of surgery serum glucose } \\
\quad(\mathrm{mg} / \mathrm{dL}, \text { mean } \pm \mathrm{SD})^{*}\end{array}$ & $129.4 \pm 40.5$ & $124.7 \pm 53.6$ & $147.5 \pm 69.9$ & \\
\hline \multicolumn{5}{|l|}{ Operative } \\
\hline \multicolumn{5}{|l|}{ Operative status (no.) } \\
\hline Elective* & $58(43.3 \%)$ & $1416(50.8 \%)$ & $1071(61.6 \%)$ & \\
\hline Urgent* & $69(51.5 \%)$ & $1307(46.9 \%)$ & $609(35.0 \%)$ & \\
\hline Emergency & $7(5.2 \%)$ & $52(1.9 \%)$ & $55(3.2 \%)$ & .003 \\
\hline Left ventricular ejection fraction $(\%$, mean $\pm \mathrm{SD}) *$ & $49.4 \% \pm 13.1 \%$ & $50.8 \% \pm 12.5 \%$ & $47.5 \% \pm 11.3 \%$ & \\
\hline Crossclamp time (min, mean $\pm \mathrm{SD})$ & $74.2 \pm 33.5$ & $67.6 \pm 33.4$ & $69.1 \pm 35.3$ & .05 \\
\hline Perfusion time (min, mean $\pm \mathrm{SD}) *$ & $95.4 \pm 37.9$ & $91.5 \pm 41.9$ & $99.7 \pm 44.8$ & \\
\hline STS predicted risk mortality $(\%, \text { mean } \pm \mathrm{SD})^{*}$ & $0.2 \% \pm 1.1 \%$ & $0.9 \% \pm 1.9 \%$ & $2.3 \% \pm 3.2 \%$ & \\
\hline
\end{tabular}

Tight, $\leq 126 \mathrm{mg} / \mathrm{dL}$; moderate, $127-179 \mathrm{mg} / \mathrm{dL}$; liberal, $\geq 180 \mathrm{mg} / \mathrm{dL}$; STS, Society of Thoracic Surgeons. $* P<.001$.

glucose control did not independently influence major complications, the risk-adjusted odds of major complications were reduced by $30 \%$ with moderate control relative to liberal goals (Table 4).

\section{DISCUSSION}

This study was designed to evaluate our institutional performance and identify the optimal glucose management strategy after isolated coronary revascularization. We found major complications and 30-day mortality to be lowest among patients with moderate glycemic control. Moreover, moderate postoperative glycemic control was independently associated with a lower incidence of major complications than was tight control and was independently associated with improved survival relative to liberal control. We used the liberal control group as our reference because poor outcomes after liberal glycemic goals are well documented and our tight control group was disproportionately small. These findings corroborate recent data from other specialties. ${ }^{2,3,14,23}$ Acute ischemic stroke and myocardial infarction are both significantly increased among patients who have stress-induced hyperglycemia, irrespective of diabetes status. ${ }^{24-27}$ It is well known that patients with diabetes have a lower mortality risk when admitted to the hospital than do patients without diabetes who have surges in glycemic index. ${ }^{1,6,28,29}$ Furthermore, our findings are consistent with the recent review that evaluated the importance of tight glucose control (80-110 $\mathrm{mg} / \mathrm{dL}$ ) in surgical patients, including postoperative cardiac surgical patients, and concluded that a glucose level of 140 to $180 \mathrm{mg} / \mathrm{dL}$ was associated with the best risk-benefit ratio. ${ }^{11}$ In addition, a recent meta-analysis of 11,425 patients concluded that there was no evidence to support the use of intensive insulin therapy in general medical and surgical ICU patients. ${ }^{30}$

Several authors have evaluated the optimal perioperative glucose management in critically ill patients, including those undergoing cardiac operations. ${ }^{7,15,31}$ Postoperative glucose management after cardiovascular procedures has been extensively reviewed by the Portland Diabetic 
TABLE 2. Postoperative outcomes by glucose management group

\begin{tabular}{|c|c|c|c|c|}
\hline Variables & Tight $(\mathbf{n}=134)$ & Moderate $(\mathbf{n}=\mathbf{2 7 8 5})$ & Liberal $(n=1739)$ & $P$ value \\
\hline First postoperative glucose $(\mathrm{mg} / \mathrm{dL} \text {, mean } \pm \mathrm{SD})^{*}$ & $115.2 \pm 29.3$ & $126.2 \pm 41.5$ & $178.3 \pm 65.6$ & \\
\hline Postoperative glucose $(\mathrm{mg} / \mathrm{dL}, \text { mean } \pm \mathrm{SD})^{*}$ & $118.98 \pm 6.2$ & $152.4 \pm 14.8$ & $214.6 \pm 30.2$ & \\
\hline \multicolumn{5}{|l|}{ Complications (no.) } \\
\hline Permanent stroke & $4(2.9 \%)$ & $35(1.3 \%)$ & $35(2.0 \%)$ & .06 \\
\hline Gastrointestinal event & $1(0.8 \%)$ & $47(1.7 \%)$ & $43(2.5 \%)$ & .11 \\
\hline Deep sternal wound infection & $2(1.5 \%)$ & $13(0.5 \%)$ & $10(0.6 \%)$ & .27 \\
\hline Multiorgan dysfunction & $1(0.8 \%)$ & $30(1.1 \%)$ & $13(0.8 \%)$ & .52 \\
\hline Atrial fibrillation & $28(20.9 \%)$ & $553(19.9 \%)$ & $366(21.1 \%)$ & .62 \\
\hline Sepsis & $5(3.7 \%)$ & $27(0.9 \%)$ & $25(1.4 \%)$ & .01 \\
\hline Prolonged ventilation* & $22(16.4 \%)$ & $166(5.9 \%)$ & $108(6.2 \%)$ & \\
\hline Renal failure* & $12(8.9 \%)$ & $97(3.5 \%)$ & $108(6.2 \%)$ & \\
\hline Dialysis* & $10(7.5 \%)$ & $29(1.0 \%)$ & $2(0.1 \%)$ & \\
\hline \multicolumn{5}{|l|}{ Resource utilization (no.) } \\
\hline Ventilator $(\mathrm{h}$, mean $\pm \mathrm{SD})$ & $38.8 \pm 171.1$ & $19.8 \pm 134.9$ & $32.5 \pm 95.0$ & .19 \\
\hline Intensive care unit ( $h$, mean $\pm \mathrm{SD}$ ) & $86.7 \pm 178.7$ & $53.4 \pm 164.6$ & $63.6 \pm 162.6$ & .10 \\
\hline Postoperative stay $(\mathrm{d} \text {, mean } \pm \mathrm{SD})^{*}$ & $8.5 \pm 11.7$ & $6.0 \pm 7.4$ & $6.6 \pm 8.0$ & \\
\hline \multicolumn{5}{|l|}{ Primary outcomes } \\
\hline Major complications* & $26(19.4 \%)$ & $308(11.1 \%)$ & $247(14.2 \%)$ & \\
\hline Mortality & $4(2.9 \%)$ & $56(2.0 \%)$ & $59(3.4 \%)$ & .02 \\
\hline
\end{tabular}

Project, which has advocated tight glucose control (70-120 $\mathrm{mg} / \mathrm{dL}$ ) with the use of continuous insulin therapy. Important work by Lazar and colleagues ${ }^{32}$ has also been cited in support of tight glycemic control after coronary revascularization. Moreover, the STS Practice Guideline Series on Blood Glucose Management During Adult Cardiac Surgery suggests that serum glucose levels should be maintained at or below $180 \mathrm{mg} / \mathrm{dL}$ to reduce mortality. Supporting these recommendations, our study found that patients with 3-day postoperative average serum glucose levels greater than $180 \mathrm{mg} / \mathrm{dL}$ had the highest mortality of any group.

Contradictory findings from the randomized singlecenter Belgian experience reported by Van den Berghe ${ }^{7}$ and the multicontinent NICE-SUGAR trial, ${ }^{15}$ both of which

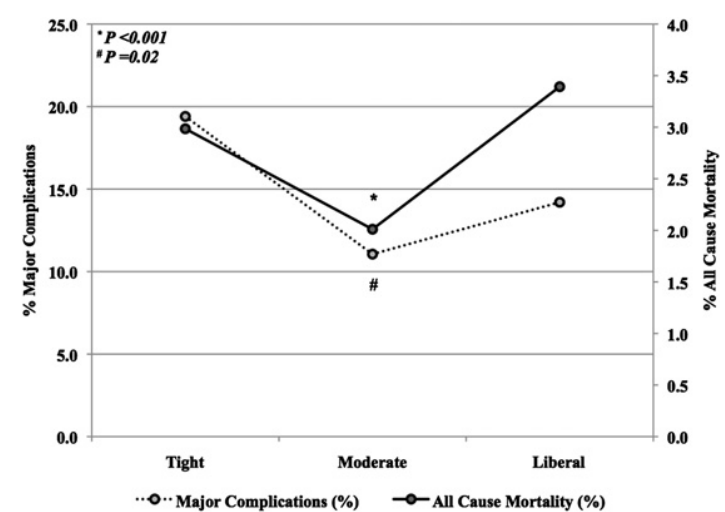

FIGURE 2. Major complications and mortality by group. Data shown reflect percentage of major complications and mortality by serum glucose levels. included patients in cardiovascular ICUs, have led to further confusion of the optimal glucose strategy. Despite their groundbreaking contribution, Van den Berghe and colleagues have drawn criticism for an underpowered design with unique patient characteristics, intensive care enteral feeding protocols, and timing of insulin therapy. ${ }^{33,34}$ Three recent prospective trials that included surgical patients failed to replicate findings from the initial study by Van den Berghe supporting tight glucose control, including one (nonsurgical patients) by Van den Berghe's own group. ${ }^{2,16,17}$

TABLE 3. Multivariable regression for predictors of mortality

\begin{tabular}{lccc}
\hline \multicolumn{1}{c}{ Covariates } & $\begin{array}{c}\text { Adjusted odds } \\
\text { ratio }\end{array}$ & $\begin{array}{c}\mathbf{9 5} \% \text { Confidence } \\
\text { interval }\end{array}$ & $\begin{array}{c}\boldsymbol{P} \\
\text { value }\end{array}$ \\
\hline Patient age (y) & 1.1 & $1.03-1.07$ & $<.001$ \\
Female sex & 2.4 & $1.62-3.62$ & $<.001$ \\
Stroke & 1.9 & $1.09-3.35$ & .02 \\
Diabetes & 0.9 & $0.62-1.44$ & .79 \\
Renal failure & 7.1 & $4.64-10.78$ & $<.001$ \\
Heart failure & 1.4 & $0.87-2.12$ & .17 \\
Preoperative steroid use & 1.8 & $0.83-4.02$ & .14 \\
Left ventricular & 0.9 & $0.95-0.98$ & $<.001$ \\
$\quad$ ejection fraction $(\%)$ & & & \\
Previous coronary & 2.4 & $1.27-4.47$ & .007 \\
$\quad$ artery bypass operation & & & \\
Previous valve operation & 3.8 & $0.67-21.13$ & .13 \\
Nonelective status & 1.5 & $1.00-2.25$ & .05 \\
Glucose control* & & & \\
$\quad$ Tight & 0.5 & $0.17-1.51$ & .22 \\
$\quad$ Moderate & 0.6 & $0.37-0.83$ & .004 \\
\hline
\end{tabular}

*Reference is liberal glucose control. 
TABLE 4. Multivariable regression for predictors of major complications

\begin{tabular}{lccc}
\hline \multicolumn{1}{c}{ Covariates } & $\begin{array}{c}\text { Adjusted odds } \\
\text { ratio }\end{array}$ & $\begin{array}{c}\mathbf{9 5} \% \text { Confidence } \\
\text { interval }\end{array}$ & $\begin{array}{c}\boldsymbol{P} \\
\text { value }\end{array}$ \\
\hline Patient age (y) & 1.0 & $1.01-1.03$ & $<.001$ \\
Female sex & 1.5 & $1.24-1.88$ & $<.001$ \\
Stroke & 1.2 & $0.86-1.74$ & .25 \\
Diabetes & 1.2 & $1.00-1.51$ & .04 \\
Renal failure & 10.1 & $7.90-12.89$ & $<.001$ \\
Heart failure & 1.5 & $1.16-1.86$ & .001 \\
Preoperative steroid use & 0.9 & $0.49-1.50$ & .59 \\
Left ventricular & 0.9 & $0.98-0.99$ & $<.001$ \\
$\quad$ ejection fraction $(\%)$ & & & \\
Previous coronary & 1.7 & $1.12-2.48$ & .01 \\
$\quad$ artery bypass operation & & & \\
Previous valve operation & 0.6 & $0.11-3.40$ & .56 \\
Nonelective status & 1.6 & $1.31-1.94$ & $<.001$ \\
Glucose control* & & & \\
$\quad$ Tight & 1.0 & $0.60-1.70$ & .97 \\
$\quad$ Moderate & 0.7 & $0.58-0.87$ & .001 \\
\hline *Reference is liberal glucose & & &
\end{tabular}

*Reference is liberal glucose control.

Several studies have attempted to address this dichotomy of strict versus less strict postoperative glucose control, and 2 treatment dogmas have evolved. The first is that of tight postoperative glycemic control (upper threshold of $120 \mathrm{mg} / \mathrm{dL}$ ), and the second is that of normoglycemic or moderate glycemic control (upper threshold of $200 \mathrm{mg} / \mathrm{dL}$ ). ${ }^{6,28,32,35,36}$ Our study supports maintaining levels between 126 and $180 \mathrm{mg} / \mathrm{dL}$, because our highest mortality was seen in the liberal management group. We did not demonstrate superior results with tight glycemic control, and we therefore question whether this is necessary in light of the risks of hypoglycemia.

The importance of glucose variance cannot be understated. In a recent retrospective report by Hermanides and coworkers $^{37}$ on surgical ICU patients, serum glucose variance when combined with high serum glucose levels was associated with the highest mortality. Often, the greatest challenge is ensuring consistent postoperative glycemic control. Unfortunately, in this study we were unable to assess the degree of glucose variance, because data were collected by the repository as a cumulative average of glucose measurements.

In addition, we use point-of-care assessment, results of which have been known to differ from arterial blood gasderived serum glucose levels by as much as $10 \%$. As such, the initial approval of glucometers by the Food and Drug Administration, with a known and accepted variance of $15 \%$, was intended for optimizing outpatient and ambulatory glycemic management, and not for determining rigorous intensive care. Finally, according to the current literature there may be differences as great as $20 \%$ between point-of-care testing and reference laboratory values of serum glucose levels.
During the course of this study, as at most institutions, our insulin protocols have evolved. From 1995 to 1999, our primary method of treating postoperative hyperglycemia in the cardiovascular ICU was physician directed and guided by attending cardiovascular surgeons according to the best practices at the time. From 1999 to 2005, we adapted the Portland Diabetic Project for glucose management for our postoperative cardiovascular patients. ${ }^{5}$ Routinely, the average of serum glucose measurements taken every 2 hours per 24 hour period was used to follow postoperative trends. From 2005 to 2008, glycemic management continued to evolve to a point at which hourly measurements were collected for trending and treatment for patients receiving an insulin infusion, with at least 18 glucose measurements for patients not receiving an infusion. Subsequent data interpretation led to the recent (2009) protocol change at our institution, so that now patients (irrespective of unit or operative status) are managed with a more relaxed postoperative glucose goal $(\leq 180 \mathrm{mg} / \mathrm{dL})$.

There are several limitations to note. Because this is a retrospective analysis, an inherent bias limits our ability to analyze variables outside of the STS database. The dissimilar patient cohorts sorted by glucose thresholds diminish prospective inference. The use of mean perioperative serum glucose measures prevents commenting on the influences on outcomes of disease chronicity, outpatient management profile, and short-term fluctuations in glycemic management. In addition, our sample size is not large enough to stratify patients according to known diabetes and perioperative hyperglycemia to answer the optimal glucose control question. Importantly, as stated previously, we attempted to identify all patients with known (including poorly controlled) or undiagnosed diabetes mellitus and stressinduced insulin resistance. Furthermore, we included diabetes and glucose control strategy in our multivariate analysis. Our results were derived from analyzing a heterogeneous cohort of patients across multiple years and are influenced by the temporal bias in patient care, protocol development, and newer medications. Specifically, our analysis is a comparison of treatment strategies. Our 3 groups are numerically unmatched, potentially representing variability in the reported serum glucose levels, with differing risk profiles. As such, our analysis is unable to reflect on variations in preoperative individual glycemic management and the resultant influences in results. Nevertheless, we have attempted to account for these differences by using regression modeling.

\section{CONCLUSIONS}

In this retrospective analysis, our data support recent randomized trials indicating that moderate control of hyperglycemia is not inferior to tight control in critically ill patients. Importantly, we have failed to establish the superiority of tight postoperative glycemic control, and we therefore 
question the necessity of this threshold. In fact, moderate control in this study was independently associated with lower mortality and major complications among patients after isolated coronary revascularization. On the basis of our findings, we believe that moderate glycemic control $(150 \mathrm{mg} / \mathrm{dL} \pm 15 \%)$ may be superior to tight control $(\leq 126 \mathrm{mg} / \mathrm{dL})$ and entails few hypoglycemic events. Further randomized prospective studies evaluating the optimal postoperative glycemic regimen are necessary.

We thank Kenneth W. Scully and Judy G. Smith for their assistance with data collection and editorial perspective.

\section{References}

1. Knapik P, Nadziakiewicz P, Urbanska E, Saucha W, Herdynska M, Zembala M. Cardiopulmonary bypass increases postoperative glycemia and insulin consumption after coronary surgery. Ann Thorac Surg. 2009;87:1859-65.

2. Gandhi GY, Nuttall GA, Abel MD, Mullany CJ, Schaff HV, O’Brien PC, et al. Intensive intraoperative insulin therapy versus conventional glucose management during cardiac surgery: a randomized trial. Ann Intern Med. 2007;146: 233-43.

3. Chan RP, Galas FR, Hajjar LA, Bello CN, Piccioni MA, Auler JO Jr. Intensive perioperative glucose control does not improve outcomes of patients submitted to open-heart surgery: a randomized controlled trial. Clinics (Sao Paulo). 2009;64:51-60.

4. Lecomte P, Foubert L, Nobels F, Coddens J, Nollet G, Casselman F, et al. Dynamic tight glycemic control during and after cardiac surgery is effective, feasible, and safe. Anesth Analg. 2008;107:51-8.

5. Zerr KJ, Furnary AP, Grunkemeier GL, Bookin S, Kanhere V, Starr A. Glucose control lowers the risk of wound infection in diabetics after open heart operations. Ann Thorac Surg. 1997;63:356-61.

6. Estrada CA, Young JA, Nifong LW, Chitwood WR Jr. Outcomes and perioperative hyperglycemia in patients with or without diabetes mellitus undergoing coronary artery bypass grafting. Ann Thorac Surg. 2003;75:1392-9.

7. van den Berghe G, Wouters P, Weekers F, Verwaest C, Bruyninckx F, Schetz M, et al. Intensive insulin therapy in the critically ill patients. N Engl J Med. 2001; 345:1359-67.

8. Furnary AP, Zerr KJ, Grunkemeier GL, Starr A. Continuous intravenous insulin infusion reduces the incidence of deep sternal wound infection in diabetic patients after cardiac surgical procedures. Ann Thorac Surg. 1999;67:352-62.

9. Furnary AP, Gao G, Grunkemeier GL, Wu Y, Zerr KJ, Bookin SO, et al. Continuous insulin infusion reduces mortality in patients with diabetes undergoing coronary artery bypass grafting. J Thorac Cardiovasc Surg. 2003;125:1007-21.

10. Furnary AP, Wu Y, Bookin SO. Effect of hyperglycemia and continuous intravenous insulin infusions on outcomes of cardiac surgical procedures: the Portland Diabetic Project. Endocr Pract. 2004;10(Suppl. 2):21-33.

11. Preiser JC, Devos P. Clinical experience with tight glucose control by intensive insulin therapy. Crit Care Med. 2007;35(9 Suppl):S503-7.

12. Devos P, Preiser JC. Current controversies around tight glucose control in critically ill patients. Curr Opin Clin Nutr Metab Care. 2007;10:206-9.

13. Surviving Sepsis Campaign Guidelines Committee Subgroup for Glucose Control, Dellinger RP, SSC Executive Committee. Surviving Sepsis Campaign statement on glucose control in severe sepsis (June 2009). Available at: http:// www.survivingsepsis.org/Guidelines/Pages/default.aspx. Accessed November 1,2010 .

14. Wiener RS, Wiener DC, Larson RJ. Benefits and risks of tight glucose control in critically ill adults: a meta-analysis. JAMA. 2008;300:933-44. Erratum in: JAMA. 2009;301:936.

15. Finfer S, Chittock DR, Su SY, Blair D, Foster D, et al., NICE-SUGAR Study Investigators. Intensive versus conventional glucose control in critically ill patients. $N$ Engl J Med. 2009;360:1283-97.

16. Van den Berghe G, Wilmer A, Hermans G, Meersseman W, Wouters PJ, Milants I, et al. Intensive insulin therapy in the medical ICU. $N$ Engl J Med. 2006;354:449-61.

17. Brunkhorst FM, Engel C, Bloos F, Meier-Hellmann A, Ragaller M, Weiler N, et al. Intensive insulin therapy and pentastarch resuscitation in severe sepsis. N Engl J Med. 2008;358:125-39.
18. Ulate KP, Lima Falcao GC, Bielefeld MR, Morales JM, Rotta AT. Strict glycemic targets need not be so strict: a more permissive glycemic range for critically ill children. Pediatrics. 2008;122:e898-904

19. Shahian DM, O'Brien SM, Filardo G, Ferraris VA, Haan CK, Rich JB, et al. The Society of Thoracic Surgeons 2008 cardiac surgery risk models: part 1-coronary artery bypass grafting surgery. Ann Thorac Surg. 2009;88 (1 Suppl):S2-22.

20. Furnary AP, Braithwaite SS. Effects of outcome on in-hospital transition from intravenous insulin infusion to subcutaneous therapy. Am J Cardiol. 2006;98: 557-64.

21. Lazar HL, McDonnell M, Chipkin SR, Furnary AP, Engelman RM, Sadhu AR, et al. The Society of Thoracic Surgeons practice guideline series: blood glucose management during adult cardiac surgery. Ann Thorac Surg. 2009;87:663-9.

22. Alberti KG, Zimmet PZ. Definition, diagnosis and classification of diabetes mellitus and its complications. Part 1: diagnosis and classification of diabetes mellitus provisional report of a WHO consultation. Diabet Med. 1998;15:539-53.

23. Ouattara A, Lecomte P, Le Manach Y, Landi M, Jacqueminet S, Platonov I, et al Poor intraoperative blood glucose control is associated with a worsened hospital outcome after cardiac surgery in diabetic patients. Anesthesiology. 2005;103 687-94.

24. Davies MJ, Lawrence IG. DIGAMI (Diabetes Mellitus, Insulin Glucose Infusion in Acute Myocardial Infarction): theory and practice. Diabetes Obes Metab. 2002;4(5):289-95.

25. Malmberg K, Norhammar A, Rydén L. Insulin treatment post myocardial infarction: the DIGAMI study. Adv Exp Med Biol. 2001;498:279-84.

26. Malmberg K, Rydén L, Wedel H, Birkeland K, Bootsma A, Dickstein K, et al Intense metabolic control by means of insulin in patients with diabetes mellitus and acute myocardial infarction (DIGAMI 2): effects on mortality and morbidity. Eur Heart J. 2005;26:650-61.

27. Kagansky N, Levy S, Knobler H. The role of hyperglycemia in acute stroke. Arch Neurol. 2001;58:1209-12.

28. McAlister FA, Man J, Bistritz L, Amad H, Tandon P. Diabetes and coronary artery bypass surgery: an examination of perioperative glycemic control and outcomes. Diabetes Care. 2003;26:1518-24.

29. Jones KW, Cain AS, Mitchell JH, Millar RC, Rimmasch HL, French TK, et al. Hyperglycemia predicts mortality after CABG: postoperative hyperglycemia predicts dramatic increases in mortality after coronary artery bypass graft surgery. J Diabetes Complications. 2008;22:365-70.

30. Marik PE, Preiser JC. Toward understanding tight glycemic control in the ICU: a systematic review and metaanalysis. Chest. 2010;137:544-51.

31. Furnary AP, Wu Y. Eliminating the diabetic disadvantage: the Portland Diabetic Project. Semin Thorac Cardiovasc Surg. 2006;18:302-8.

32. Lazar HL, Chipkin SR, Fitzgerald CA, Bao Y, Cabral H, Apstein CS. Tight glycemic control in diabetic coronary artery bypass graft patients improves perioperative outcomes and decreases recurrent ischemic events. Circulation. 2004;109: 1497-502.

33. Myburgh JA, Chittock DR. Differences in outcome between the NICE-SUGAR and Leuven trials: biological mechanisms of intensive glucose control in critically ill patients. Crit Care Resusc. 2009;11:178-9.

34. Henderson WR, Finfer S. Differences in outcome between the NICE-SUGAR and Leuven trials: possible methodological explanations. Crit Care Resusc. 2009;11:175-7.

35. Markovitz LJ, Wiechmann RJ, Harris N, Hayden V, Cooper J, Johnson G, et al Description and evaluation of a glycemic management protocol for patients with diabetes undergoing heart surgery. Endocr Pract. 2002;8:10-8.

36. Finney SJ, Zekveld C, Elia A, Evans TW. Glucose control and mortality in critically ill patients. JAMA. 2003;290:2041-7.

37. Hermanides J, Vriesendorp TM, Bosman RJ, Zandstra DF, Hoekstra JB Devries JH. Glucose variability is associated with intensive care unit mortality. Crit Care Med. 2010;38:838-42.

\section{Discussion}

Dr Anthony P. Furnary (Portland, Ore). Dr Ailawadi, since I have to make this short, I really can't make it sweet. I thought your title was very clever, but the simple statistical fact is that neither the title nor the conclusions are supported in any way by the data presented, nor is it possible that any difference between tight 
and moderate control, if it did actually exist, could have ever been statistically detected in this study.

Let me explain. There are 134 patients in the tight group and 2700 in the moderate group. Because of the lack of a sufficient number of patients in the tight group, the study was markedly underpowered to detect any differences between the tight and moderate groups. Power analysis reveals that the estimated power of this study to detect a $1 \%$ absolute reduction in mortality between these 2 groups was only $3 \%$, nowhere near the $80 \%$ power sought to ensure a valid finding. A quick $\chi^{2}$ analysis comparing your mortality data between these 2 groups shows a $P$ value of .6. Even if there had been no deaths at all in the tight group, the $P$ value would have still been insignificant at .1.

Furthermore, your study is based entirely on retrospective data abstracted from an administrative — read "billing"- -database. Not a clinical database, not an STS database, an administrative database. Clinical outcomes from these databases are "assumed" by interpreting coding information that is applied to patient charts by hospital coders after discharge. Then, rather than using established STS predicted risk scores, which you had, for logistic risk adjustment, a new regression model was created.

What you have shown is that moderate control is superior to no control at all, and this is a finding that is supported by 15 years of published literature on the subject. Moderate control reduced mortality by $40 \%$ relative to no control. Interestingly, the point estimate for tight control shows a $50 \%$ reduction in mortality relative to the no control group. Again, however, there weren't enough patients to bring that point estimate to statistical significance; even had there been no deaths at all in the tight control group, it wouldn't have made it into the equation. To take those results and imply that moderate control is superior to tight control when they weren't even directly compared, simply because it didn't make it into the equation because of the low number of patients, is either wishful thinking or misleading marketing rhetoric that is not supported by your statistical data.

I have similar concerns about your morbidity statistics and conclusions. I don't have time to go into them here. In addition, however, of the 5 major complications that you have analyzed, 3 of them-stroke, prolonged ventilation, and reoperation-have never ever been shown to be associated with, let alone caused by, hyperglycemia in cardiac surgical patients. Thus the treatment studied, glycemic control, is unrelated to the complications examined. It would be like looking at the effect of antibiotics on atrial fibrillation rate.

We all know our first responsibility is to our patients, and we all come to this meeting looking for a sound bite, something we can take home, something that we can implement in our practice. It just worries me that the conclusion that you present, that moderate control is "superior" to tight control, is a dangerous message to let out, because the simple fact is that it is not supported by your data.

I have 3 questions. First, you cite moderate control articles from the medical ICU literature that don't include patients undergoing CABG. Why should we as cardiac surgeons ignore both randomized and observational cardiac-specific trials totaling more than 36,000 patients that tell us that the optimal target for patients undergoing CABG is in the range of 80 to $130 \mathrm{mg} / \mathrm{dL}$ in deference to your $134 \mathrm{mg} / \mathrm{dL}$ tight glycemic control patients?
Dr Ailawadi. Thank you for your comments. Getting back to the comment about our use of a clinical data repository, these data were merged with our STS database. We did use our STS data, not purely administrative data. We actually merged the data sets. So we believe that this actually provides better data and more complete data, because the STS, as you know, does not include many of these things that we are examining.

With the comment about stroke having never been associated with glucose strategy, there was a randomized trial of 400 patients by Gandhi published a couple of years ago comparing tight glucose control with a more liberal or a more moderate glucose control, similarly to our study. It was a randomized study, and they did find a worse stroke rate in patients with tight control. I realize that it is not a perfect study, but that has been shown before.

In terms of the question about medical intensive care unit, if you actually look at the NICE-SUGAR trial, although the article does not specify the number of patients who underwent cardiac surgery, it did include both medical and surgical patients. If you actually look, some of the centers included were cardiovascular ICUs.

Dr Furnary. I am going to respond really quickly. First, there were no patients undergoing CABG in that trial, or at least certainly fewer than 100 . Second, the Gandhi trial only studied intraoperative glycemic control, and the postoperative control was the same between groups. It was a very bad study.

My next question, and I think I know your answer to this, is in light of the serious statistical issues I have raised - and they are serious-would you consider restating your conclusion and retitling your article? Because you actually compared moderate control with no control, not moderate to tight.

Dr Ailawadi. The moderate control was not compared with no control; it was a more liberal control. It was essentially what was being done for many years until data became available.

Dr Furnary. Right, so it is moderate versus liberal.

Dr Ailawadi. It was a physician-directed protocol that many believe was the best at the time.

Dr Furnary. Would you agree that your study does not compare moderate versus tight control?

Dr Ailawadi. I would agree that our reference group is the liberal control group, not the tight control group, because the latter cannot be a reference group with only 134 patients.

Dr Furnary. So you compared moderate control with your reference group but not moderate control with tight control?

Dr Ailawadi. And we compared tight control with the reference group as well.

Dr Furnary. Thank you. So, finally, last question. With tight control in Portland, our 3-day blood glucose average is $115 \mathrm{mg}$ / $\mathrm{dL}$ and our diabetes-associated CABG mortality in the last 10 years among more than 2000 such patients is $0.9 \%$, with an STS observed to expected ratio of 0.25 , a quarter of the national average mortality. So why do you think that the STS-derived observed to expected ratios contained within your data, but not explicitly presented, of 13.6 for tight control, 2.3 for moderate, and 1.45 for no control, were all significantly greater than 1 ?

Dr Ailawadi. Well, there are many potential reasons. Obviously, we are in a different situation, being at a training center, than you are at your institution. And although I cannot address that as the sole reason, an overall CABG mortality of roughly $2 \%$ is pretty similar to what the literature shows and what the 
STS shows. I know that there has been an issue to try to get it down to $1 \%$, and perhaps this will help us to do that, but I do believe that tight control may not be necessary.

I would want to emphasize that glucose control is a necessary thing. The question is, how tight do we really need to be? And if there are worse mortalities and higher complications with a tight strategy, then these findings of our study will be borne out in future randomized studies. So this is not the be-all and end-all; I agree with that. I think that this is an interesting study. We were a bit surprised to see the findings, and I think it should lead to better questioning in the future.

Dr Furnary. Thanks. I am sorry to rain on your parade. I think there is another rainmaker over there.

Dr Harold L. Lazar (Boston, Mass). I just need to disclose that we do have research support from the Eli Lilly Company but own no stock in the company.

When I heard that Dr Furnary was going to discuss this presentation, I didn't think that I would have too much more to question or add, but I would like to ask a couple of questions. When we wrote the guidelines for the STS a couple of years ago, we stated that the optimal glucose range would be between 120 to $180 \mathrm{mg} /$ $\mathrm{dL}$, and we did so not really to endorse tight versus moderate but to make it easier for people to have at least some compliance. Subsequently, our own group has done a study in which we looked at moderate versus aggressive control in a prospective randomized fashion, comparing 90 to $120 \mathrm{mg} / \mathrm{dL}$ versus 120 to $180 \mathrm{mg} / \mathrm{dL}$. And what we found was that the tighter control group had better control of inflammatory factors such as free fatty acids, but in reality when we looked at the clinical end points and all the major adverse cardiac and cerebrovascular events, there was absolutely no difference.

So my first question to you is, why do you think that tight glycemic control was detrimental? We have seen that it may not add any more-at least in the short term, we can't comment on the long term - but why should it be bad? And in answering this question, I would like to ask you to focus on these points. What was the lowest glucose level that was reached? Did you actually have a formal protocol that actually titrated the glucose to achieve a certain level? And how often did you measure glucose, and what did you do when you reached the level that was lower, let's say, than $80 \mathrm{mg} / \mathrm{dL}$ ?

Dr Ailawadi. Excellent questions. So the first question is, why do we think this is bad? And, again, we don't have data on the number of hypoglycemic events, but that is certainly a concern. There has been a fair amount of literature on the effects of neuroglycopenia, and, many patients in our population were still in the ICU, some of them still intubated. Those are difficult to assess, at least clinically, and merely can be measured with a glucose measurement.
In terms of the lowest glucose level reached, we had patients whose serum mean glucose levels were basically were as low as about 85 to $90 \mathrm{mg} / \mathrm{dL}$.

Did we have a formal protocol? Before 1999, it was a physician-directed protocol. It was not a protocol enforced by the institution. From 1999, on we adopted the Portland protocol, which has since been modified as STS guidelines have improved, and we follow the STS guidelines quite carefully.

Dr Robert Scott Kramer (Portland, Me). We need to interpret the evidence supporting tight glycemic control with regard to the context where execution of the protocol at the bedside is the key to success. Well-trained and well-supervised bedside nurses can make a significant difference in the safety of a tight glycemic control program. Some nurses can manage an algorithm-driven insulin drip with the skill of a pilot keeping an airplane flying straight and level. I suspect that the NICE-SUGAR trial may have had some problems with the execution of the protocol at the bedside, because its hypoglycemia rate was so high. The lesson from NICE-SUGAR is that hypoglycemia is dangerous. Drs Furnary and Van den Berghe and others have taught us that a tight glycemic control protocol executed well at the bedside improves outcomes.

Dr Ailawadi. I believe that we have taken glucose control very seriously at the University of Virginia since the Portland diabetic project was first published. We have a number of people who are very interested in this, endocrinologists, nursing staff, and administrators, and our university is taking a very aggressive systemwide hospital approach. So I do believe that we feel very strongly that this is an important thing that we have undertaken.

Finally, in response to the question about how often we measure, in the past it had been a minimum of 12 measurements during a 24-hour period. That has now increased to a minimum of 18 measurements during a 24-hour period.

Dr Lazar. I am anxious to add just a follow-up to that. I think that the lack of a proper controlled regimen and not following these patients on an hourly basis and making adjustments may be contributory to some of the effects, because that is where people who have noted problems with tight glycemic control in surgical patients have gotten into trouble.

I guess my second question is, as we know, tight glycemic control is not only important in the first 24 hours but is important after the first 24 hours and before the patient goes home. So what protocols did you have in effect to look at the effect of glycemic control once the patient has left the ICU?

Dr Ailawadi. Essentially our strategy is when patients are receiving insulin infusions, we do get hourly blood glucose levels. When patients get out of the ICU from postoperative day 1 to 3 , they are transitioned gradually to a sliding scale and the insulin infusion is turned off. This is all by protocol. 